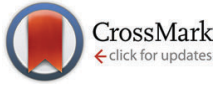

Cite this: New J. Chem., 2015, 39,8337

Received (in Nottingham, UK) 27th June 2015 , Accepted 10th August 2015

DOI: 10.1039/c5nj01664a

www.rsc.org/njc

\section{A BODIPY/pyridine conjugate for reversible fluorescence detection of gold(III) ions $\dagger$}

\author{
Muhammed Üçüncü, Erman Karakuş and Mustafa Emrullahoğlu*
}

\begin{abstract}
We designed a "turn-on" type fluorescent probe based on a BODIPY-pyridine conjugate which exhibits high selectivity towards $\mathrm{Au}(\mathrm{III})$ ions and, also responds to changes in the $\mathrm{pH}$ within the acidic $\mathrm{pH}$ range. The probe offers features such as a rapid response time, a low detection limit, and high sensitivity and selectivity. The detection of $\mathrm{Au}(\mathrm{III})$ is recognized by a distinct change in the emission intensity which relies on a reversible "ligand to ion" binding mechanism. We also document the utility of the probe for the quantification of gold ion residues in synthetic end products prepared via gold catalysis.
\end{abstract}

\section{Introduction}

During the last decade, the catalytic properties of gold have attracted a surge of attention in the field of synthetic chemistry. Ionic species of gold, in contrary to elemental gold, have the exceptional capability to activate unsaturated bonds (e.g. alkyne) towards the addition of nucleophiles. ${ }^{1-5}$ Besides their peerless catalytic activities, gold ions present interesting biological properties. For a long time, certain drugs based on various gold ion complexes have been used in the treatment of diseases including rheumatic arthritis, cancer, asthma, and HIV..$^{6-8}$ In contrast to their beneficial roles in disease treatment, the intake of gold ions can be toxic to living organisms because of the possibility of the interaction with biomolecules such as enzymes and DNA. Numerous scientific studies have established the detrimental effects of gold species on vital human organs. For instance, the intake of $\mathrm{AuCl}_{3}$ causes damage to the kidneys, liver, and the peripheral nervous system. ${ }^{9-11}$

The potential health hazards associated with gold species pushes the demand for developing trustable and efficient methods to detect trace levels of gold species existing in synthetic chemicals prepared via gold catalysis.

Trace metal analysis relying on fluorescence techniques are very popular nowadays. ${ }^{12-16}$ In contrast to the traditional instrumental techniques, fluorescence-based techniques have many preferable advantages such as low cost, simplicity, high sensitivity and reproducibility. Several gold ion selective molecular sensors utilizing various fluorophore units - including rhodamine, ${ }^{17-21}$ BODIPY, ${ }^{22-25}$ fluorescein, ${ }^{26,27}$ naphthalimide, ${ }^{28,29}$ and coumarin ${ }^{30}$ dyes - have been developed over the last few years. ${ }^{31,32}$ The great

Department of Chemistry, Faculty of Science, Izmir Institute of Technology, Urla, 35430, Izmir, Turkey. E-mail: mustafaemrullahoglu@iyte.edu.tr

$\dagger$ Electronic supplementary information (ESI) available: Absorbance and fluorescence data and all experimental procedures. See DOI: 10.1039/c5nj01664a majority of the sensors present in the literature are based on irreversible chemical events, which take advantage of the alkynophilic behaviour of gold species. In general, a fluorophore core integrated with a gold ion specific reactive unit (i.e. alkyne), will transform the action of the gold ions into a fluorescence signal output either through a change in the fluorescence wavelength or a change in the fluorescence intensity. ${ }^{33}$ Notably, one chronic issue in reaction-based gold ion sensing is the potential of other alkynophilic metal species to interfere with the detection of the gold ions. Thus, new sensing strategies utilizing alternative recognition events need to be developed in order to improve the general shortcomings of reaction based sensing strategies.

In this regard, molecular sensors relying on reversible ion-dipole interactions appear to be good alternatives to reaction-based molecular sensors. Interestingly, however, molecular sensors which operate reversibly towards gold ions are extremely scarce, most predominantly due to the challenges of design and synthesis. $^{34}$

Herein, we present the design, synthesis and spectral properties of BOD-Pyr, a novel turn-on type fluorescent chemosensor that allows both $\mathrm{Au}^{3+}$ and $\mathrm{H}_{3} \mathrm{O}^{+}$ions to be detected on the basis of reversible ion-dipole interactions. Knowing the capability of pyridine to act as a ligand for ionic gold species, we envisioned that a pyridine motif, when integrated with a fluorophore core, could act as a specific recognition motif for gold ions. Several BODIPY-pyridine conjugates have been reported in the literature which respond to changes in $\mathrm{pH}$ or to certain metal species such as $\mathrm{Cu}^{2+}$ and $\mathrm{Hg}^{2+} \cdot{ }^{35-37}$

With all this in mind, we designed a molecular structure, which comprises a BODIPY dye as the fluorophore unit and a pyridylethenyl motif as the recognition site. The BODIPY core was the fluorophore of choice owing to its exceptional photophysical properties such as high photo stability, high fluorescence quantum yield, robustness towards light and chemicals, and long emission/absorption wavelengths. ${ }^{38-41}$ 


\section{Results and discussion}

BOD-Pyr was prepared by the synthetic route outlined in Scheme 1 . First, a Vilsmeier Haack's formylation reaction of BODIPY-1 gave BODIPY-2, ${ }^{42}$ which in the final step was treated with an appropriate Wittig reagent to give exclusively the $E$-isomer of the title compound in a reasonable yield of $c a .56 \%$ (Scheme 1). The chemical structure of BOD-Pyr was clearly confirmed by performing NMR spectroscopy and HRMS analysis.

\section{$\mathrm{Au}^{3+}$ sensing properties of BOD-Pyr}

The photophysical behaviour of BOD-Pyr in response to a series of metal species was carried out by both UV-vis absorption and fluorescence spectroscopy. We commenced our investigation by first determining the optimum conditions for the recognition of $\mathrm{Au}^{3+}$ ions. A variety of solvent combinations involving EtOH- $\mathrm{H}_{2} \mathrm{O}$, DMF- $\mathrm{H}_{2} \mathrm{O}$, and $\mathrm{CH}_{3} \mathrm{CN}-\mathrm{H}_{2} \mathrm{O}$ (Fig. S1, ESI $\dagger$ ) were screened. Furthermore, the ratio of water in the semi-aqueous environment and the effect of the $\mathrm{pH}$ on the sensing process were carefully investigated. Eventually, the optimum conditions for the sensing process were established as a $0.1 \mathrm{M}$ phosphate buffer/EtOH $(\mathrm{pH}=7.0, \mathrm{v} / \mathrm{v}, 1: 1)$ with a $10 \mu \mathrm{M}$ dye concentration (Fig. S2 and S3, ESI $\dagger$ ).

The spectral changes of BOD-Pyr in the absence and presence of $\mathrm{Au}^{3+}$ ions are displayed in Fig. 1. As shown, free BOD-Pyr exhibits a faint fluorescence emission centered at $591 \mathrm{~nm}$. $\left(\Phi_{\mathrm{F}}=0.044\right)$. However, the addition of $\mathrm{Au}^{3+}$ (6 equiv.) to BOD-Pyr results in an observable enhancement of the emission intensity together with a slight blue shift in the emission wavelength $\left(\lambda_{\mathrm{em}}=577 \mathrm{~nm}\right)$ in a very short time $(30 \mathrm{~s})$ (Fig. S4, ESI $\left.\dagger\right)$. This spectral

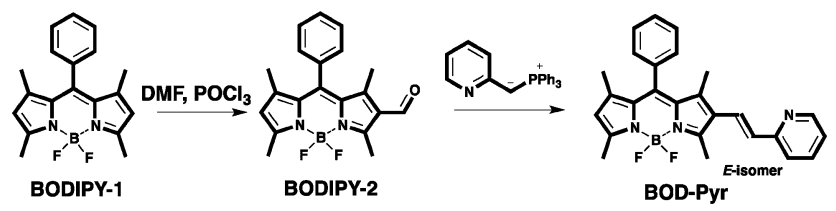

Scheme 1 Synthetic route for BOD-Pyr.

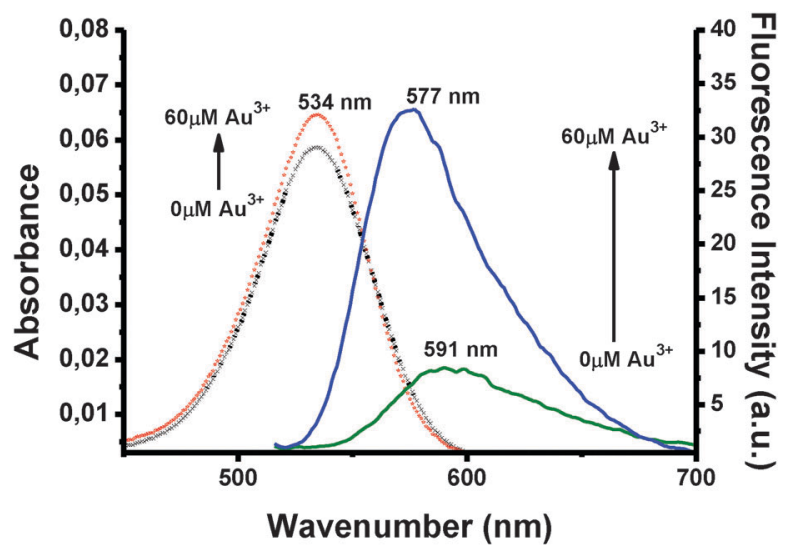

Fig. 1 Absorbance spectra of BOD-Pyr $(10 \mu \mathrm{M})$ in the absence (black dotline) and presence (red dot-line) of 6 equiv. $(60 \mu \mathrm{M})$ of $\mathrm{Au}^{3+}$ and fluorescence spectra of BOD-Pyr $(10 \mu \mathrm{M})$ in the absence (green line) and presence (blue line) of 6 equiv. $(60 \mu \mathrm{M})$ of $\mathrm{Au}^{3+}$ in a $0.1 \mathrm{M}$ phosphate buffer/EtOH (pH = 7.0, v/v, 1:1). behaviour of BOD-Pyr is suggested to be due to the complexation of $\mathrm{AuCl}_{3}$ with the lone pair of electrons of the pyridylethenyl unit, which terminates the overall PET-quenching process.

Importantly, neither the absorption nor the fluorescence emission wavelength of BOD-Pyr was affected by changing the polarity of the sensing medium which indicates that BOD-Pyr has indeed no solvatochromic behaviour.

The selectivity profile of BOD-Pyr was surveyed by screening the spectral response towards metal species including $\mathrm{Zn}^{2+}$, $\mathrm{Cd}^{2+}, \mathrm{Ba}^{2+}, \mathrm{Cu}^{2+}, \mathrm{Li}^{+}, \mathrm{K}^{+}, \mathrm{Ni}^{2+}, \mathrm{Cr}^{2+}, \mathrm{Mg}^{2+}, \mathrm{Fe}^{3+}, \mathrm{Pb}^{2+}, \mathrm{Hg}^{2+}, \mathrm{Co}^{2+}, \mathrm{Ag}^{+}$ and $\mathrm{Au}^{+}$. Delightfully, no significant changes were measured in the presence of the other metal species. Only the addition of $\mathrm{Au}^{3+}$ and, to a lesser extent the addition of $\mathrm{Au}^{+}$resulted in an increase of fluorescence at $577 \mathrm{~nm}$, which obviously implies the high selectivity of BOD-Pyr to gold ions (Fig. S8, ESI $\dagger$ ). Fortunately, $\mathrm{Hg}^{2+}$ and $\mathrm{Pd}^{2+}$, being the most competitive metal ions in the detection of gold species did not result in any spectral change.

In order to assess the interference of other metal ions we explored the fluorescence response in the presence of other metal ions. As shown in Fig. S9 (ESI $\dagger$ ), the response of BOD-Pyr towards $\mathrm{Au}^{3+}$ was not affected in the presence of other competitive metal species. These results establish that BOD-Pyr can properly detect gold ions in mixtures of other related species.

We further investigated the binding ability of BOD-Pyr to $\mathrm{Au}^{3+}$ by performing a fluorescence titration experiment (Fig. 2 and Fig. S6, ESI $\dagger$ ). The emission intensity reached its maximum when 6 equiv. of $\mathrm{Au}^{3+}$ was added and the stoichiometry of the sensing event was established by following the Benesi-Hildebrand method and Job's plot analysis. In addition, there was a good linear relationship between the fluorescence intensity and the concentration of the $\mathrm{Au}^{3+}$ ions ( 0.2 to 0.7 equivalents of $\mathrm{Au}^{3+}$ ) (Fig. S10, $\mathrm{ESI} \dagger$ ). From this data the detection limit of BOD-Pyr was evaluated as $4.0 \mu \mathrm{M}$. A straight line was obtained from the plot of $\ln \left[\left(F-F_{0}\right) /\right.$ $\left.\left(F_{\max }-F\right)\right]$ against $\ln \left[\mathrm{Au}^{3+}\right]$ and the related binding constant was determined to be $4.9 \times 10^{4} \mathrm{M}^{-2}$. Moreover, the Job's plot analysis supported a 2:1 stoichiometry for the complexation. Despite great efforts, we failed to grow a single crystal of the binding complex suitable for XRD analysis in order to confirm the binding stoichiometry.

The specific binding of $\mathrm{Au}^{3+}$ to the pyridine ligand was clearly followed by the aid of ${ }^{1} \mathrm{H}$-NMR spectroscopy. Upon the binding of $\mathrm{AuCl}_{3}$ with BOD-Pyr, the pyridine ring protons $\left(\mathrm{H}_{\mathrm{b}}\right.$, $\mathrm{H}_{\mathrm{c}}$ and $\mathrm{H}_{\mathrm{d}}$ ) of the binding complex were dramatically shifted to a higher frequency (downfield shift), consistent with the coordination of nitrogen to $\mathrm{AuCl}_{3}$ (Fig. 3b and Fig. S15, ESI $\dagger$ ).

Further experiments revealed that the binding ability of BOD-Pyr to $\mathrm{Au}^{3+}$ could be dramatically improved in non-aqueous sensing media. For example in DCE the binding constant was evaluated to be $1.8 \times 10^{5} \mathrm{M}^{-2}$, which was visibly greater than that measured in aqueous media (Fig. S14, ESI $\dagger$ ).

In non-aqueous sensing media, where the effects of solvation are minimized, the complexation of $\mathrm{Au}^{3+}$ to the BODIPY-pyridine conjugate gave a 20-fold fluorescence enhancement, which is visibly greater than the fluorescence increase observed in aqueous media. Similar to the measurements carried out in aqueous conditions, the fluorescence titration profile of BOD-Pyr with $\mathrm{Au}^{3+}$ 

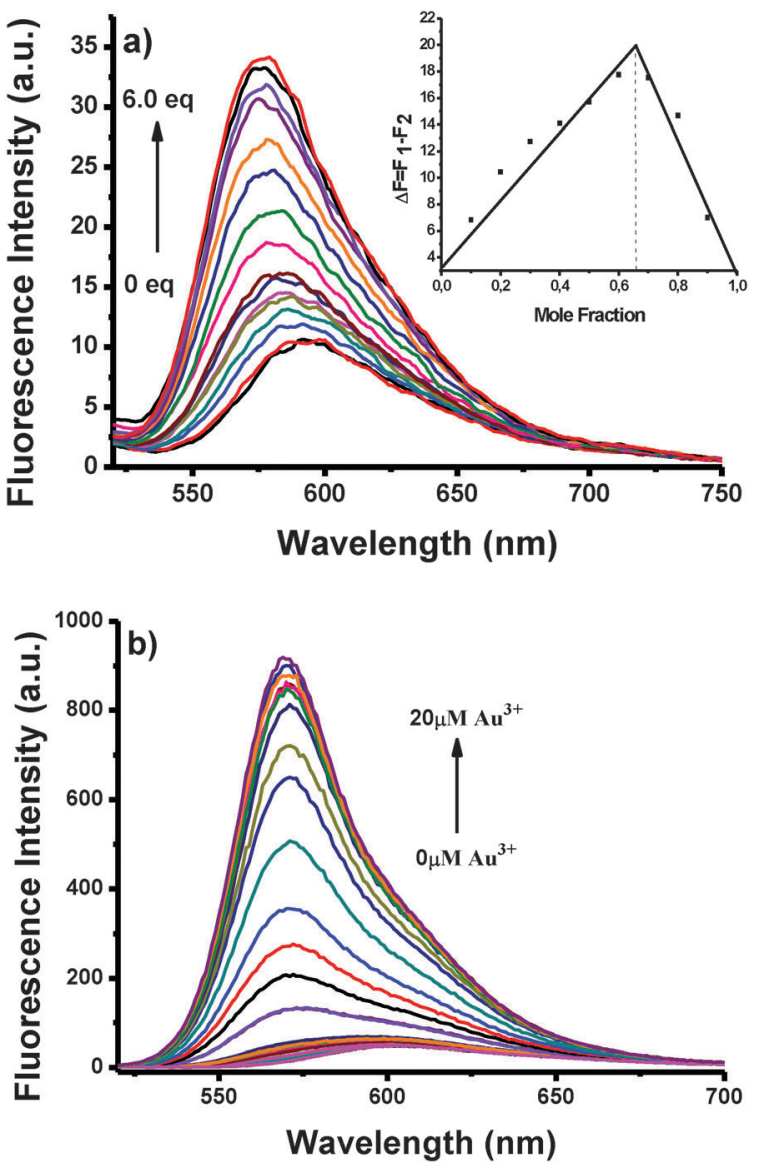

Fig. 2 Fluorescence spectra of BOD-Pyr $(10 \mu \mathrm{M})$ in the presence of increasing concentrations of $\mathrm{Au}^{3+}$ (a) $(0-60 \mu \mathrm{M}, 0-6$ equiv.) in a $0.1 \mathrm{M}$ phosphate buffer/EtOH $(\mathrm{pH}=7.0, \mathrm{v} / \mathrm{v}, 1: 1)\left(\lambda_{\text {exc }}=500 \mathrm{~nm}\right.$ at $\left.25^{\circ} \mathrm{C}\right)$ and (b) $(0-20 \mu \mathrm{M}, 0-2$ equiv.) in DCE. Inset: Job's plot analysis between BOD-Pyr and $\mathrm{Au}^{3+}$. The total concentration of BOD-Pyr and $\mathrm{Au}^{3+}$ was kept constant at $20 \mu \mathrm{M}$.
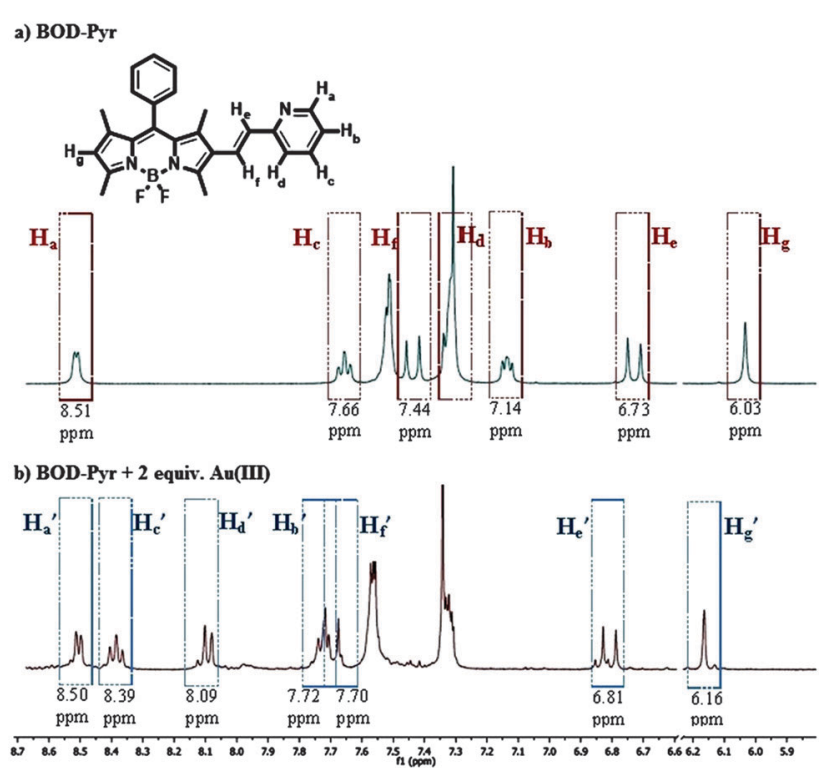

Fig. 3 (a) Partial ${ }^{1} \mathrm{H}$ NMR spectra of BOD-Pyr and (b) BOD-Pyr $+\mathrm{AuCl}_{3}$ (2 equiv.).

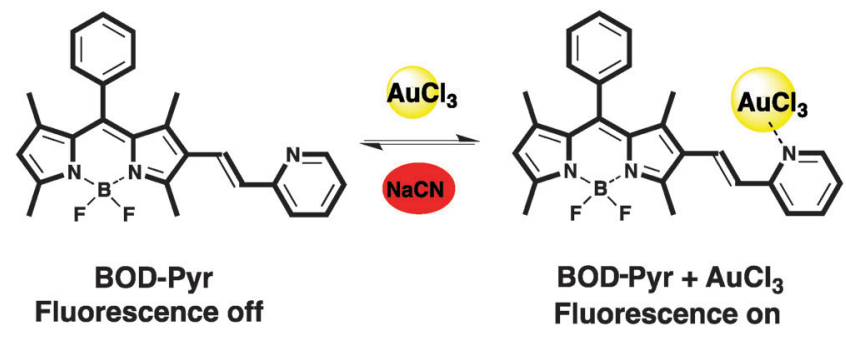

Scheme 2 Reversible interaction of BOD-Pyr with $\mathrm{Au}^{3+}$.

in a non-aqueous medium showed a linear relationship for the concentration range of $0.05-1.0 \mu \mathrm{M}$ (Fig. S16, ESI $\dagger$ ). Notably, the detection limit of BOD-Pyr was significantly improved to nanomolar levels $(63 \mathrm{~nm}, \mathrm{~S} / \mathrm{N}>3)$. However, it is worth mentioning here that, despite the improved sensitivity, the selectivity towards $\mathrm{Au}^{3+}$ was dramatically decreased in non-aqueous media.

The sensing mechanism of the probe was designed to be reversible. To get insight into whether the sensing mechanism is reversible or not, an excess amount of $\mathrm{CN}^{-}$ions ( $\mathrm{NaCN}, 6.0$ equiv.) were introduced into a solution containing $10 \mu \mathrm{M}$ of dye and 6.0 equivalents of $\mathrm{Au}^{3+}(0.1 \mathrm{M}$ phosphate buffer/EtOH $(\mathrm{pH}=7.0, \mathrm{v} / \mathrm{v}$, 1:1)). As shown in Fig. S12 (ESI $\dagger$ ), the fluorescence intensity of the probe solution was immediately reduced by the addition of $\mathrm{CN}^{-}$ which proves the reversibility of the recognition process (Scheme 2).

\section{Response of BOD-Pyr toward pH changes}

In addition to being exceptionally selective towards $\mathrm{Au}^{3+}$ ions, BOD-Pyr is also sensitive to changes in $\mathrm{pH}$ within the acidic $\mathrm{pH}$ range. Free BOD-Pyr, which exhibits a faint fluorescence emission at $591 \mathrm{~nm}$ in the $\mathrm{pH}$ range of 7-12, gave an immediate strong emission band at $564 \mathrm{~nm}$ upon protonation of the pyridylethenyl moiety (Fig. 4b). As the pH of the solution decreased from 7.0 to 2.0 , concomitantly the emission intensity increased by 18 -fold. The quantum yield of BOD-Pyr at $\mathrm{pH}=2.0$, was determined to be 0.39 using rhodamine $6 \mathrm{G}\left(\Phi_{\mathrm{F}}=0.95\right.$ in ethanol) as a standard dye.

As for the gold sensing process, BOD-Pyr operates in a reversible manner towards the detection of hydronium ions (Scheme 3). The reversible interaction between BOD-Pyr and $\mathrm{H}_{3} \mathrm{O}^{+}$was confirmed by the addition of $\mathrm{OH}^{-}$ions to the acidified probe solution (BOD-Pyr $+\mathrm{H}_{3} \mathrm{O}^{+}$) which resulted in a sharp decrease in the emission intensity.

The regeneration of the fluorescence was possible by introducing $\mathrm{H}_{3} \mathrm{O}^{+}$ions into the solution. Obviously, the "off-on" switching ability of the system proves the reversibility of the process (Fig. 5). In addition, the acidity constant $\mathrm{p} K_{\mathrm{a}}$ of the probe was established using the Henderson-Hasselbalch equation (Fig. S20, ESI $\dagger$ ). A linear fit was obtained within the range of $\mathrm{pH}$ from 2.0 to 6.0 and the $\mathrm{p} K_{\mathrm{a}}$ value was calculated to be $3.06 \pm$ (0.14). All of these results indicate that BOD-Pyr can be utilized on demand as a "turn-on" fluorescent probe for monitoring acidity changes within the $\mathrm{pH}$ range of 7.0-2.0.

\section{Quantitative detection of residual $\mathrm{Au}^{3+}$}

In order to assess whether BOD-Pyr could be applied for the monitoring of residual $\mathrm{Au}^{3+}$ ions in a synthetic end-product we 

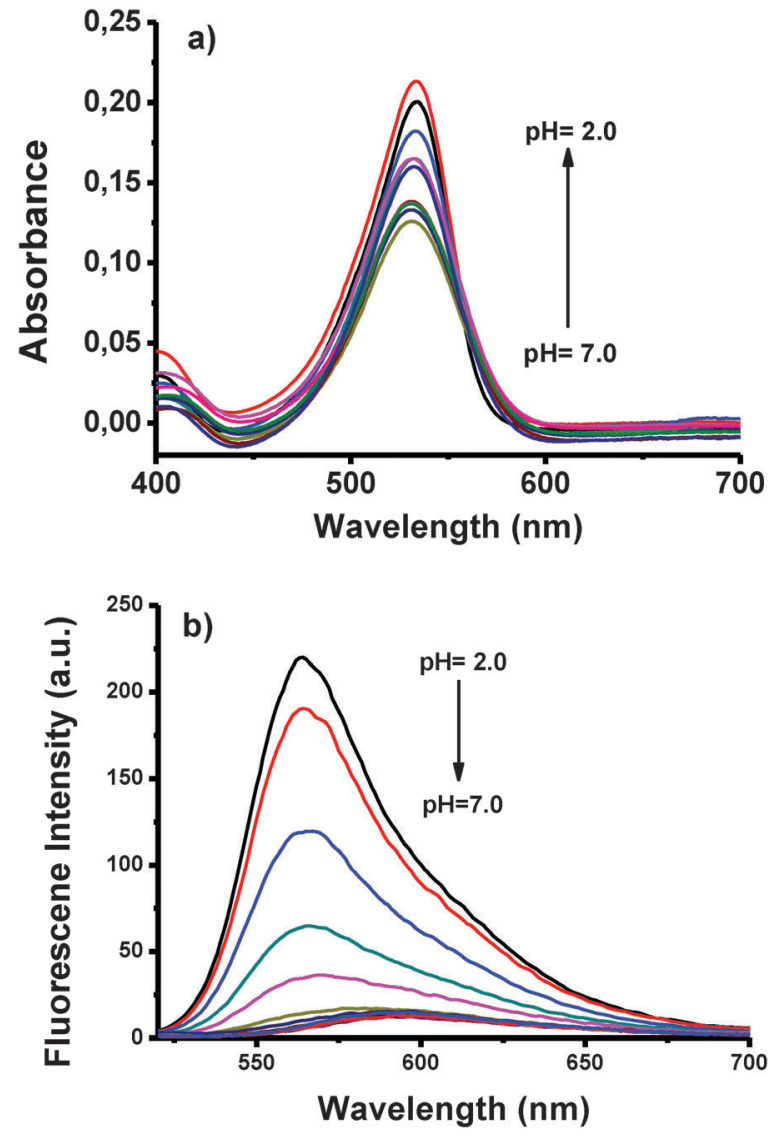

Fig. 4 (a) Absorbance and (b) fluorescence spectra of BOD-Pyr $(10 \mu \mathrm{M})$ in a $0.1 \mathrm{M}$ phosphate buffer/EtOH $(\mathrm{v} / \mathrm{v}, 1: 1)$ at various $\mathrm{pH}$ values $(2.0-7.0)$ $\left(\lambda_{\text {exc }}=500 \mathrm{~nm}, 25^{\circ} \mathrm{C}\right.$ ).

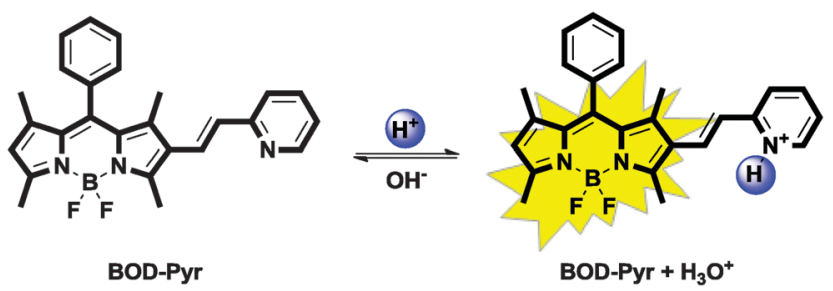

Scheme 3 Reversible protonation of BOD-Pyr.

performed a known chemical transformation utilizing $\mathrm{AuCl}_{3}$ as the active catalyst. ${ }^{43}$ To this end, a propargylic amide derivative in dichloromethane was rapidly transformed into its Oxazole derivative under the catalysis of $\mathrm{AuCl}_{3}(10 \mathrm{~mol} \%)$ (Scheme 4).

The crude product of the chemical reaction was subjected to chromatographic purification using silica as the stationary phase and dichloromethane as an eluent. A defined amount of the purified sample ( $2 \mathrm{mg}$ ) was added to a solution of BODPyr $(10 \mu \mathrm{M}$ in a $0.1 \mathrm{M}$ phosphate buffer/EtOH $(\mathrm{pH}=7.0, \mathrm{v} / \mathrm{v}$, 1:1)). Immediately, a distinct change in colour and fluorescence was observed in the probe solution indicating the presence of gold species in the solution. This observation is consistent with previous literature reports, where others have

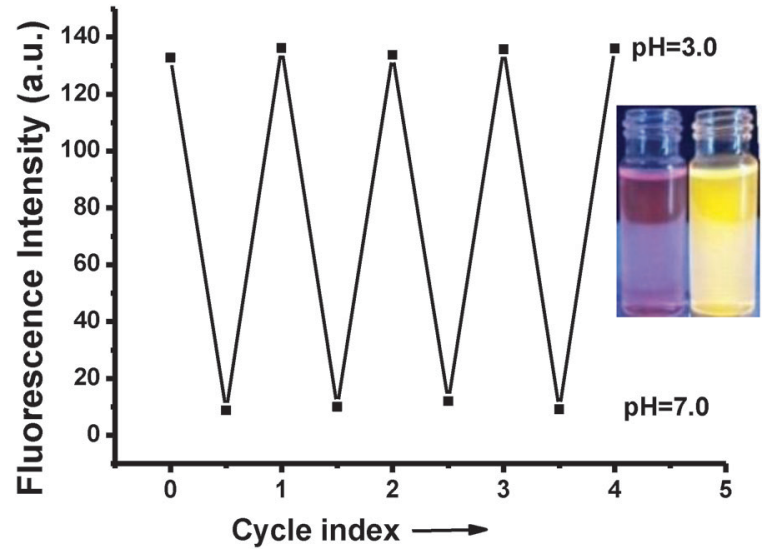

Fig. $5 \mathrm{pH}$ reversibility study of BOD-Pyr $(10 \mu \mathrm{M})$ between the $\mathrm{pH}$ values of 7.0 and 3.0 in water/EtOH (v/v, 1:1) $\left(\lambda_{\text {exc }}=500 \mathrm{~nm}, \lambda_{\mathrm{em}}=564 \mathrm{~nm}, 25^{\circ} \mathrm{C}\right)$. Inset: fluorescence photograph of BOD-Pyr at pH = 7.0 (left) and 3.0 (right) under illumination with $365 \mathrm{~nm}$ light.

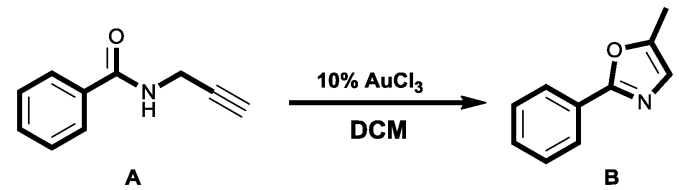

Scheme $4 \quad \mathrm{AuCl}_{3}$ catalysed cyclization reaction of propargyl amide.

proven that a synthetic end product may still contain residues of the metal catalyst even after chromatographic purification.

By the aid of fluorescence measurements the gold content in the sample solution was measured to be $1.8 \times 10^{-8} \mathrm{~mol} \mathrm{mg}^{-1}$ based on a standard calibration curve (Fig. S16, ESI $\dagger$ ). This result was also consistent with that obtained by inductively coupled plasma mass spectrometry (ICP-MS) analysis $\left(1.27 \times 10^{-8} \mathrm{~mol} \mathrm{mg}^{-1}\right)$. With this experiment we unambiguously confirmed the viability of BOD-Pyr for quantitative gold analysis.

\section{Conclusions}

To close, we have constructed a dual response fluorescent chemosensor for the rapid detection of gold species and, also for monitoring changes in acidity $(\mathrm{pH}=2-7)$. This novel chemosensor (BOD-Pyr) comprises a pyridylethenyl unit as the recognition site and a BODIPY core as the fluorophore unit. The sensing mechanism of BOD-Pyr is based on the selective binding of gold ions to the pyridyl nitrogen atom which is recognized by a distinct change in the emission intensity. Importantly, BOD-Pyr represents a rare example of a fluorescent probe that operates "reversibly" towards gold species. As a practical application we have successfully documented the utility of BOD-Pyr for the quantification of gold ion residues in synthetic chemicals that were prepared via gold catalysis.

\section{Experimental section}

\section{General methods}

All reagents were purchased from commercial suppliers (Aldrich and Merck) and they were used without further purification. 
${ }^{1} \mathrm{H}$ NMR and ${ }^{13} \mathrm{C}$ NMR were measured on a Varian VNMRJ 400 Nuclear Magnetic Resonance Spectrometer. A Bruker MALDI-TOF mass spectrometer was used for mass spectrometry analysis. The UV absorption spectra were obtained on a Shimadzu UV-2550 spectrophotometer. The fluorescence measurements were performed by using a Varian Cary Eclipse fluorescence spectrophotometer. Samples were placed in $10.0 \mathrm{~mm}$ path length quartz cuvettes $(2.0 \mathrm{~mL}$ volume). Upon excitation at $500 \mathrm{~nm}$, the emission spectra were integrated over the range of $520 \mathrm{~nm}$ to $750 \mathrm{~nm}$. The slit width was $5 \mathrm{~nm}$ for both excitation and emission. The melting points were determined by using an Electrothermal Melting Point Apparatus 9200. The $\mathrm{pH}$ was recorded by a HI-8014 instrument (HANNA). All measurements were conducted at least in triplicate.

\section{Synthesis of BOD-Pyr}

To a solution of BODIPY-2 (100 mg, $0.285 \mathrm{mmol})$ in dioxane $(10 \mathrm{~mL})$ was added triphenyl(2-pyridylmethyl)phosphonium chloride hydrochloride (389 mg, $0.896 \mathrm{mmol}$ ). Then, $250 \mu \mathrm{L}$ of triethyl amine was added drop by drop and the resultant solution was stirred at room temperature overnight. After the reaction was complete, the solution was concentrated under vacuum and was extracted three times with dichloromethane. The organic layer was dried over sodium sulfate and was concentrated under reduced pressure. The resultant residue was purified by silica gel column chromatography (hexane/ethyl acetate (8/1)) to afford BOD-Pyr as a green solid (68.1 mg, 56\% yield). Mp: 267-269 ${ }^{\circ} \mathrm{C} .{ }^{1} \mathrm{H}$ NMR $\left(400 \mathrm{MHz}, \mathrm{CDCl}_{3}\right) \delta: 8.56(\mathrm{~d}, J=4.0 \mathrm{~Hz}$, $1 \mathrm{H}), 7.62\left(\mathrm{~d}_{\mathrm{t}}, J=8.0,1.6 \mathrm{~Hz} 1 \mathrm{H}\right), 7.52-7.50(\mathrm{~m}, 3 \mathrm{H}), 7.46(\mathrm{~s}, 1 \mathrm{H}), 7.32-$ $7.29(\mathrm{~m}, 2 \mathrm{H}), 7.28(\mathrm{~s}, 1 \mathrm{H}), 7.12-7.09(\mathrm{~m}, 1 \mathrm{H}), 6.72(\mathrm{~d}, J=16.0 \mathrm{~Hz}, 1 \mathrm{H})$, $6.01(\mathrm{~s}, 1 \mathrm{H}), 2.76(\mathrm{~s}, 3 \mathrm{H}), 2.58(\mathrm{~s}, 3 \mathrm{H}), 1.51(\mathrm{~s}, 3 \mathrm{H})$ and $1.38(\mathrm{~s}, 3 \mathrm{H}) \cdot{ }^{13} \mathrm{C}$ NMR $\left(100 \mathrm{MHz}, \mathrm{CDCl}_{3}\right) \delta: 156.3,155.9,154.9,149.6,143.8,141.8$, 139.3, 136.5, 135.0, 132.0, 131.0, 129.5, 129.2, 129.1, 128.1, 127.8, 123.9, 121.8, 121.8, 14.7, 14.5, 14.1 and 12.9. Calcd for $\mathrm{C}_{26} \mathrm{H}_{24} \mathrm{BF}_{2} \mathrm{~N}_{3}$ : 427.203 [M] $]^{+}$, found: $428.244[\mathrm{M}+\mathrm{H}]^{+}$.

\section{Acknowledgements}

We thank the İzmir Institute of Technology (IZTECH) and TUBITAK for financial support.

\section{Notes and references}

1 I. Braun, A. M. Asiri and A. S. K. Hashmi, ACS Catal., 2013, 3, 1902.

2 Z. Li, C. Brouwer and C. He, Chem. Rev., 2008, 108, 3239.

3 A. Arcadi, Chem. Rev., 2008, 108, 3266.

4 A. S. K. Hashmi and M. Rudolph, Chem. Soc. Rev., 2008, 37, 1766.

5 N. Krause and C. Winter, Chem. Rev., 2011, 111, 1994.

6 C. F. Shaw III, Chem. Rev., 1999, 99, 2589.

7 I. Ott, Coord. Chem. Rev., 2009, 253, 1670.

8 M. Navarro, Coord. Chem. Rev., 2009, 253, 1619.

9 C. M. Goodman, C. D. McCusker, T. Yilmaz and V. M. Rotello, Bioconjugate Chem., 2014, 15, 897.

10 A. Habib and M. Tabata, J. Inorg. Biochem., 2004, 98, 1696.
11 W. D. Block and E. L. Knapp, J. Pharmacol. Exp. Ther., 1945, 83, 275.

12 X. Li, X. Gao, W. Shi and H. Ma, Chem. Rev., 2014, 114, 590.

13 K. P. Carter, A. M. Young and A. E. Palmer, Chem. Rev., 2014, 114, 4564.

14 X. Chen, T. Pradhan, F. Wang, J. S. Kim and J. Yoon, Chem. Rev., 2012, 112, 1910.

15 X. Su and I. Aprahamian, Chem. Soc. Rev., 2014, 43, 1963.

16 Z. Guo, S. Park, J. Yoon and I. Shin, Chem. Soc. Rev., 2014, 43, 16.

17 M. J. Jou, X. Chen, K. M. K. Swamy, H. N. Kim, H.-J. Kim, S. G. Lee and J. Yoon, Chem. Commun., 2009, 7218.

18 O. A. Egorova, H. Seo, A. Chatterjee and K. H. Ahn, Org. Lett., 2010, 12, 401.

19 Y. K. Yang, S. Lee and J. Tae, Org. Lett., 2009, 11, 5610.

20 L. Yuan, W. Lin, Y. Yang and J. Song, Chem. Commun., 2011, 47, 4703.

21 M. Emrullahoğlu, E. Karakuş and M. Üçüncü, Analyst, 2013, 138, 3638.

22 J.-B. Wang, Q.-Q. Wu, Y.-Z. Min, Y.-Z. Liu and Q.-H. Song, Chem. Commun., 2012, 48, 744.

23 E. Karakuş, M. Üçüncü and M. Emrullahoğlu, Chem. Commun., 2014, 50, 1119.

24 M. Üçüncü and M. Emrullahoğlu, Chem. Commun., 2014, 50, 5884 .

25 M. Üçüncü, E. Karakuş and M. Emrullahoğlu, Chem. - Eur. J., 2015, DOI: 10.1002/chem.201502411.

26 H. Seo, M. E. Jun, O. A. Egorova, K. H. Lee, K. T. Kim and K. H. Ahn, Org. Lett., 2012, 14, 5062.

27 N. Y. Patil, V. S. Shinde, M. S. Thakare, P. H. Kumar, P. R. Bangal, A. K. Barui and C. R. Patra, Chem. Commun., 2012, 48, 11229.

28 M. Dong, Y.-W. Wang and Y. Peng, Org. Lett., 2010, 12, 5310. 29 J. Y. Choi, G.-H. Kim, Z. Guo, H. Y. Lee, K. M. K. Swamy, J. Pai, S. Shin, I. Shin and J. Yoon, Biosens. Bioelectron., 2013, 49, 438.

30 J. H. Do, H. N. Kim, J. Yoon, J. S. Kim and H.-J. Kim, Org. Lett., 2010, 12, 932.

31 Z. Öztaş, M. Pamuk and F. Algi, Tetrahedron, 2013, 69, 2048. 32 Y. Yang, C. Yin, F. Huo and J. Chao, RSC Adv., 2013, 3, 9637. 33 S. Singha, D. Kim, H. Seo, S. W. Cho and K. H. Ahn, Chem. Soc. Rev., 2015, 44, 4367.

34 J. Wang, W. Lin, L. Yuan, J. Song and W. Gao, Chem. Commun., 2011, 47, 12506.

35 E. Deniz, G. C. Isbasar, Ö. A. Bozdemir, L. T. Yıldırım, A. Siemiarczuk and E. U. Akkaya, Org. Lett., 2008, 10, 3401.

36 S. Wagner, K. Brödner, B. A. Coombs and U. H. F. Bunz, Eur. J. Org. Chem., 2012, 2237.

37 L. Zhou, C.-C. Zhu, Y.-S. Xue, W.-J. He, H.-B. Du, X.-Z. You and Y.-Z. Li, Inorg. Chem. Commun., 2013, 35, 355.

38 N. Boens, V. Leen and W. Dehaen, Chem. Soc. Rev., 2012, 41, 1130. 39 R. Ziessel, G. Ulrich and A. Harriman, New J. Chem., 2007, 31, 496. 40 A. Loudet and K. Burgess, Chem. Rev., 2007, 107, 4891.

41 G. Ulrich, R. Ziessel and A. Harriman, Angew. Chem., Int. Ed., 2008, 47, 1184.

42 M. Isik, T. Ozdemir, I. S. Turan, S. Kolemen and E. U. Akkaya, Org. Lett., 2013, 15, 216.

43 A. S. K. Hashmi, J. P. Weyrauch, W. Frey and J. W. Bats, Org. Lett., 2004, 6, 4391. 